\title{
Chromosomal imbalances in malignant peripheral nerve sheath tumor detected by metaphase and microarray comparative genomic hybridization
}

\author{
YASUKO NAKAGAWA ${ }^{1}$, AKI YOSHIDA ${ }^{1}$, KUNIHIKO NUMOTO $^{1}$, TOSHIYUKI KUNISADA ${ }^{1}$, \\ DANIEL WAI $^{2}$, NORIHIDE OHATA ${ }^{1}$, KEN TAKEDA $^{1}$, AKIRA KAWAI $^{3}$ and TOSHIFUMI OZAKI ${ }^{1}$ \\ ${ }^{1}$ Science of Functional Recovery and Reconstruction, Okayama University Graduate School of Medicine, Dentistry, \\ and Pharmaceutical Sciences, Okayama, Japan; ${ }^{2}$ Childrens Hospital Los Angeles, University of South California, \\ Los Angeles, USA; ${ }^{3}$ Department of Orthopaedic Surgery, National Cancer Center, Tokyo, Japan
}

Received June 21, 2005; Accepted August 2, 2005

\begin{abstract}
Malignant peripheral nerve sheath tumors (MPNSTs) are highly malignant tumors affecting adolescents and adults. There have been a few reports on chromosomal aberrations of MPNSTs; however, the tumor-specific alteration remains unknown. We characterized the genomic alterations in 8 MPNSTs and 8 schwannomas by metaphase comparative genomic hybridization (CGH). In 5 of 8 MPNSTs, microarray $\mathrm{CGH}$ was added for more detailed analyses. Frequent gains were identified on 3q13-26, 5p13-14, and 12q11-23 and frequent losses were at 1p31, 10p, 11q24-qter, 16, and 17. Microarray CGH revealed frequent gains of EGFR, DAB2, MSH2, KCNK12, DDX15, CDK6, and LAMA3, and losses of CDH1, GLTSCR2, EGR1, CTSB, GATA3, and SULT2A1. These genes seem to be responsible for developing MPNSTs. The concordance rate between metaphase CGH and microarray CGH was $66 \%$. Metaphase CGH was useful for identifying chromosomal alterations before applying microarray $\mathrm{CGH}$.
\end{abstract}

\section{Introduction}

The malignant peripheral nerve sheath tumor (MPNST) is a high-grade soft tissue sarcoma which accounts for 5-10\% of all soft tissue sarcomas. It frequently occurs in adolescents and young adults (1). MPNSTs are derived from two different backgrounds; $50 \%$ of cases have a hereditary neurofibromatosis type 1 (NF1) and others are sporadic. In the formation of neurofibromatosis, germ-line mutations occurring in genes, NF1 (17q11.2) and NF2 (22q), play an important role (2). MPNSTs develop in 10-14\% of NF1 patients (3). Most patients

Correspondence to: Dr Toshifumi Ozaki, Science of Functional Recovery and Reconstruction, Okayama University Graduate School of Medicine, Dentistry, and Pharmaceutical Sciences, 2-5-1 Shikata-cho, Okayama 700-8558, Japan

E-mail: tozaki@md.okayama-u.ac.jp

Key words: chromosomal imbalances, nerve sheath tumor, microarray, genomic hybridization with MPNST have previously had a benign peripheral nerve sheath tumor (BPNST) (1). However, the mechanism of malignant change from BPNST to MPNST is unknown. In recent years, there have been a few reports on chromosomal investigations of MPNSTs; CGH analyses revealed several characteristic chromosomal imbalances in a limited number of cases. NF1 (17q), NF2 (22q), p16 (9p), and EGFR (7p) alterations are reported to be involved in MPNST formation (4).

In 1998, microarray CGH technique was developed by Pinkel D et al (5) after modification of the metaphase CGH technique which was developed by Kallioniemi (6). Precise identification of each gene with copy number changes has become possible using this technique; however, there have been few reports on microarray $\mathrm{CGH}$ analyses in bone and soft tissue sarcomas. In the current study, we analyzed the chromosomal aberrations with metaphase CGH to detect the characteristic alterations in MPNSTs and to estimate the difference of chromosomal alterations between MPNSTs and schwannomas. Moreover, the aberrations detected by metaphase $\mathrm{CGH}$ were further analyzed by microarray CGH in 5 MPNSTs. The results of both techniques were compared in order to clarify the usefulness of both forms of CGH in chromosomal analyses.

\section{Materials and methods}

Tumor samples. Sixteen tumor samples were obtained by open biopsy or surgical excision at Okayama University Hospital between 1980 and 2003. These samples were preserved in a deep freezer at $-80^{\circ} \mathrm{C}$. Among them, 8 MPNSTs from 8 patients and 8 schwannomas from 8 patients, with abundant stock samples and from which DNA could be extracted, were selected for cytogenetic analysis for this study. The patient characteristics were as matched as possible, including age, gender, tumor location, and size, in both groups.

In the 8 MPNSTs, 5 tumors were primary and 3 were locally recurrent. None of the tumors had received chemotherapy or radiotherapy between relapse and excision. Four tumors were derived from 4 females and 4 from 4 males. The average age at diagnosis was 39 years (range, 11-75 years). 
Table I. Clinico-pathological data of malignant peripheral nerve sheath tumors and schwannomas.

\begin{tabular}{|c|c|c|c|c|c|c|c|c|c|c|}
\hline Case & Diagnosis & Sex & $\begin{array}{c}\text { Age } \\
\text { (years) }\end{array}$ & $\begin{array}{c}N F I \\
\text { mutation }\end{array}$ & Site & $\begin{array}{l}\text { Surgical } \\
\text { margin }^{\mathrm{a}}\end{array}$ & $\begin{array}{l}\text { Period before } \\
\text { relapse (months) }\end{array}$ & $\begin{array}{l}\text { Relapse } \\
\text { pattern }\end{array}$ & $\begin{array}{c}\text { Period of } \\
\text { survival (months) }\end{array}$ & Prognosis \\
\hline 1 & MPNST & $\mathrm{F}$ & 75 & negative & thigh & intralesional & 0 & $\begin{array}{l}\text { local and } \\
\text { metastasis }\end{array}$ & 15 & DOD \\
\hline 2 & MPNST & $\mathrm{F}$ & 34 & positive & buttock & intralesional & 3 & local & 4 & DOD \\
\hline 3 & MPNST & M & 41 & negative & thigh & wide & 19 & local & 48 & DOA \\
\hline 4 & MPNST & M & 26 & positive & $\begin{array}{l}\text { upper } \\
\text { arm }\end{array}$ & marginal & 31 & multiple & 51 & DOD \\
\hline 5 & MPNST & $\mathrm{F}$ & 53 & negative & thigh & wide & 11 & metastasis & 22 & DOD \\
\hline 6 & MPNST & $\mathrm{F}$ & 26 & positive & thigh & wide & 15 & multiple & 21 & DOD \\
\hline 7 & MPNST & M & 11 & positive & knee & marginal & 11 & $\begin{array}{l}\text { local and } \\
\text { metastasis }\end{array}$ & 25 & DOD \\
\hline 8 & MPNST & M & 49 & positive & back & wide & 13 & local & 29 & NED \\
\hline 9 & scwannoma & M & 60 & negative & back & marginal & no relapse & none & 96 & $\mathrm{CDF}$ \\
\hline 10 & scwannoma & $\mathrm{F}$ & 69 & negative & thigh & marginal & no relapse & none & 78 & $\mathrm{CDF}$ \\
\hline 11 & scwannoma & $\mathrm{F}$ & 24 & negative & hand & marginal & no relapse & none & 48 & $\mathrm{CDF}$ \\
\hline 12 & scwannoma & $\mathrm{F}$ & 24 & negative & lower leg & marginal & no relapse & none & 36 & $\mathrm{CDF}$ \\
\hline 13 & scwannoma & $\mathrm{F}$ & 48 & negative & thigh & marginal & no relapse & none & 33 & $\mathrm{CDF}$ \\
\hline 14 & scwannoma & M & 38 & negative & shoulder & marginal & no relapse & none & 33 & $\mathrm{CDF}$ \\
\hline 15 & scwannoma & M & 57 & negative & thigh & marginal & no relapse & none & 26 & $\mathrm{CDF}$ \\
\hline 16 & scwannoma & M & 61 & negative & thigh & marginal & no relapse & none & 20 & $\mathrm{CDF}$ \\
\hline
\end{tabular}

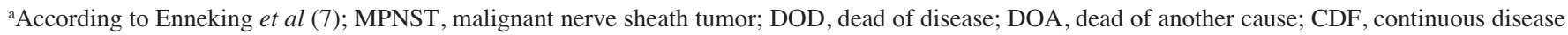
free; AWD, alive with disease.

Five patients had von Recklinghausen disease (neurofibromas type 1). All MPNSTs were high-grade tumors (stage IIB) and the surgical margins were composed of 4 wide, 2 marginal and 2 intralesional, according to the methods of Enneking et al (7). Six tumors were located in the extremities and 2 tumors were located in the trunk. Table I demonstrates the clinical and pathological data of the patients with MPNST. One patient (case 6) received chemotherapy of MAID regimen, composed of doxorubicin, ifosphamide, and dacarbazine (8), after the primary tumor excision. One patient (case 4) received a 40-gray of postoperative radiotherapy to another lesion in a different site from the primary tumor site.

All 8 schwannomas were primary and sporadic tumors. Four tumors were from 4 women and 4 from 4 men. The average age at diagnosis was 48 years (range, 24-69 years). Six tumors were located in the extremities and 2 tumors were located in the trunk. Every patient underwent marginal excision of the tumor following confirmation of the histological diagnosis by a rapid frozen section at an open biopsy. The clinical and pathological data of the patients with schwannoma appear in Table I.

The period of follow-up ranged from 8 to 84 months (average, 31.5 months). If the MPNSTs newly developed in the nerve of the different site during follow-up, they were regarded as multiple tumor occurrences. If the tumor appeared in the region adjacent to the previous operative site, the tumor was regarded as a locally relapsed tumor. If the tumor occurred in the area not related to the nerve or previous operation, the tumor was classified as a metastatic tumor. The end-point of the follow-up was August 2005.

Metaphase $C G H$. Reference DNA from healthy blood donors (male) and tumor DNA from fresh frozen tumor tissues were labeled by the nick translation method with SpectrumReddUTP (Vysis, IL, USA) and SpectrumGreen-dUTP (Vysis), respectively. Nick translation and $\mathrm{CGH}$ hybridization were performed according to the manufacturer's protocol (Vysis). Normal lymphocyte metaphase preparations were denatured at $73^{\circ} \mathrm{C}$ for $5 \mathrm{~min}$ in $70 \%$ formamide/2X SSC (pH7) and dehydrated. The probe mixture, after ethanol precipitation and re-suspension in $10 \mu \mathrm{l} \mathrm{CGH}$ buffer (Vysis), was denatured at $75^{\circ} \mathrm{C}$ for $5 \mathrm{~min}$, applied to the slides and hybridized for 3 days at $37^{\circ} \mathrm{C}$.

The hybridization was analyzed using a Leica microscope (DMRA2) (Leica Microsystems Wetzlar GmbH, Wetzlar, Germany) and the Leica Cytogenetic Workstation (CW4000) (Leica Microsystems Imaging LTD, Cambridge, UK) based on a high-sensitivity interrating CCD camera (SenSys0401E, Roper Scientific Germany, Ottobrunn, Germany) and an automated $\mathrm{CGH}$ analysis software package. Ratio profiles were averaged from 10 metaphases per sample. Gains of DNA sequences were defined as chromosomal regions with a 
Table II. Copy number changes in 8 malignant peripheral nerve sheath tumors (MPNSTs) and 8 schwannomas.

\begin{tabular}{|c|c|c|c|}
\hline Diagnosis & Case & Gain & Loss \\
\hline \multirow[t]{8}{*}{ MPNST } & 1 & 6q12-q22, 7q, 11p, 12, 13q22-qter, 18, 19, 22q & $8 \mathrm{p}, 10 \mathrm{p}, 11 \mathrm{q} 23$-qter, 16 \\
\hline & $2^{\mathrm{a}}$ & $\begin{array}{l}\text { 2, 3q24-q28, 4q, 6p, 7p, 7q11.2-q22, 8q13-qter/8q13-q23, 9q31-qter/9q34, } \\
\text { 12p11.2-p12, 14q22-q24, 15q22, 17q24, 18q22-qter, 21q21 }\end{array}$ & $6 \mathrm{q} 27,9 \mathrm{q} 12,16 \mathrm{q} 12-\mathrm{q} 22,19 \mathrm{q}, 20 \mathrm{q}$ \\
\hline & 3 & $\begin{array}{l}1 \mathrm{p} 22-\mathrm{p} 31,4 \mathrm{p} 15-\mathrm{q} 27,5 \mathrm{p} 14-\mathrm{q} 22, \mathbf{6 q}, 9 \mathrm{q} 21-\mathrm{q} 31,11 \mathrm{p} 22-\mathrm{p} 15,11 \mathrm{q} 14-\mathrm{q} 22,14 \mathrm{q} \\
15 \mathrm{q}, 18 \mathrm{q}, 21 \mathrm{q}\end{array}$ & 1q41-qter, 2qter, 16q \\
\hline & $4^{\mathrm{a}}$ & $\begin{array}{l}\text { 1p31-q31, 2, 3, 4q32-pter, 5p, 5q21-q31, 6/6q, 7p21, 8q/8q21-q22, 9q21-q32, } \\
11 \mathrm{p}, 12 \mathrm{p} 12,12 \mathrm{q} 21,14 \mathrm{q} 12-\mathrm{q} 24,15 \mathrm{q} 21,18 \mathrm{q} 12-\mathrm{qter}, 20 \mathrm{p}, 21 \mathrm{q} 21\end{array}$ & 1p34-pter, 10p, 17pter, 19p \\
\hline & 5 & $\begin{array}{l}\text { 1p12-p31, 1q24-q32, 2q32, 3q24-q26, 4, 5, 6q12-q23, 7q21-q31, 9p21-pter } \\
10 \mathrm{q} 21,11 \mathrm{p} 14,11 \mathrm{q} 22,12 \mathrm{q} 21,13 \mathrm{q} 12-\mathrm{q} 32,14 \mathrm{q} 12-\mathrm{q} 24,15 \mathrm{q} 12-\mathrm{q} 22,18 \mathrm{q} 12-\mathrm{qter}, 21 \mathrm{q} 21\end{array}$ & $19 \mathrm{p}$ \\
\hline & $6^{\mathrm{a}}$ & $\begin{array}{l}\text { 4p15-q27, 5p15-q31, 6p12-qter, 11p/11p14, 11q12-q22/11q14-q22, 12q12-q21, } \\
15 q 11-q 23,17 q 23\end{array}$ & 1q32-qter \\
\hline & $7^{\mathrm{a}}$ & $\begin{array}{l}\text { 1p31, 1q/q23, 2q22-q32, 3, 4, 5p, 6q12-q22/6q14, 7/7pter-q23, 8/8p12-q23, } \\
\text { 9q21-q22, 10p13-q21, 11p14, 11q14, 12p12-q23, 13q12-q22, 14q, 15q21, 18q, } \\
\mathbf{2 1 q}, 22 q 21\end{array}$ & 11q12, 11qter, 17pter, 17qter \\
\hline & $8^{\mathrm{a}}$ & $\begin{array}{l}\text { 1q32-qter, 2q23-q32, 3p12-q13, 3q24-q26, 4q26-q28, 5q21-q23, 6q14-q22, } \\
\text { 8q12-q22, 9p, 10q22-q23, 11q22-q23, 13q22, } 21 \text { q12 }\end{array}$ & $\begin{array}{l}1 \mathrm{p} 33-\mathrm{pter}, 9 \mathrm{q} 34,16 \mathrm{p}, 20 \mathrm{p} 12 \\
20 \mathrm{q} 13,22 \mathrm{q}\end{array}$ \\
\hline \multirow[t]{8}{*}{ schwannoma } & 9 & & $9 p, 10 p, 22 q$ \\
\hline & 10 & $1 \mathrm{q} 31$ & $12 q$ ter, $16 p, 19 q 13,22 q$ \\
\hline & 11 & $21 \mathrm{q} 22$ & $4 q 34,8 p, 9 p, 22 q$ \\
\hline & 12 & & $22 \mathrm{q}$ \\
\hline & 13 & & \\
\hline & 14 & & \\
\hline & 15 & & \\
\hline & 16 & & $8 \mathrm{p}, 20 \mathrm{q}, 22 \mathrm{q}$ \\
\hline
\end{tabular}

High-level gains are indicated in bold. aPatients with von Recklinghausen's disease.

fluorescence ratio $>1.25$ and losses as regions with a ratio $<0.75$. A positive control with known aberrations and a negative control were included in each $\mathrm{CGH}$ experiment as quality controls. Regional shifts of the fluorescence ratio profile exceeding the 1.5 threshold were rated as high-level gain. Telomeric and heterochromatic regions near the centromeres and the entire $\mathrm{X}$ and $\mathrm{Y}$ chromosomes were excluded from the analysis. The profiles of 1p32-pter, 16p, 17p, and chromosomes 19 and 22 were carefully investigated because they are known to give false-positive results. Judgement was based on a consensus of at least two of three authors in all cases without reference to the patient's clinical information.

Microarray $\mathrm{CGH}$. Preparation of the array, hybridization, and analysis were followed according to the methods of Bruder et al (9). Reference DNA and test tumor DNA samples were labeled using the Random Priming Reagent kit (Vysis). Sample DNA was labeled with $1 \mathrm{mM} \mathrm{Cy}{ }^{\mathrm{TM}}$ 3-dCTP (Perkin-Elmer, Boston, USA). This was mixed with whole genomic reference DNA that was labeled with $\mathrm{Cy}^{\mathrm{TM}}$ 5-dCTP (Perkin-Elmer). Both labeled DNA were co-hybridized to a microarray in the presence of human Cot 1 DNA. The microarray contained 287 kinds of target clone DNA (P1, PAC or BAC clones) representing regions that are important in cytogenetics and oncology, including oncogenes, tumor suppressor genes and subtelomere (GenoSensor ${ }^{\circledR}$ Array 300; Vysis). DNA clones comprising the desired target sequences were arrayed in target spots of approximately 75-125 $\mu \mathrm{m}$ diameter, whereby each clone is represented by 3 targets spots. Following hybridization, target spots are counter-stained. Arrays were imaged using the GenoSensor and the GenoSensor Reader software. The GenoSensor Reader System is a large-field multicolor fluorescence imaging system which captures an image of the hybridized chip in 3 color planes; Cy3, Cy5, and DAPI blue. The included software automatically identifies each spot and, by analysis of the set of $\mathrm{Cy} 3 / \mathrm{Cy} 5$ ratios on all targets, calculates the ratio most representative of the modal DNA copy number of the sample DNA. The normal range of ration of control DNA was defined between 1.14 and 0.86 . If the data was beyond the range of +1 and -0.15 , it was regarded as gain and loss, respectively.

\section{Results}

The clinical courses of the patients. Six of 8 patients with MPNST died from their disease, 1 patient died from another 


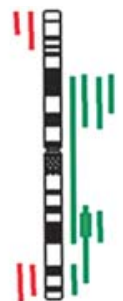

1

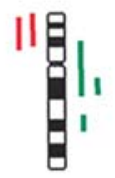

10

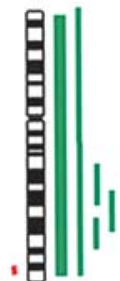

2

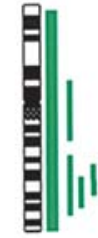

3

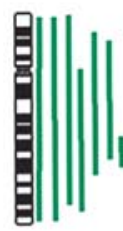

4

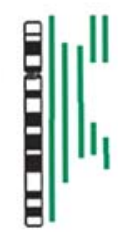

5

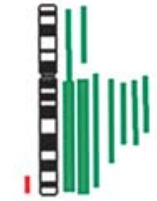

6
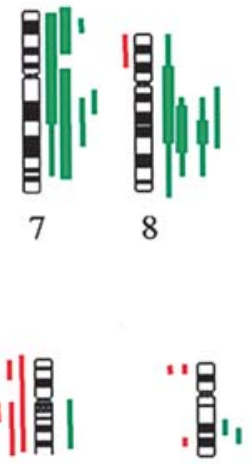

17
16

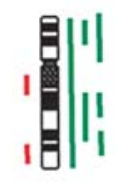

9
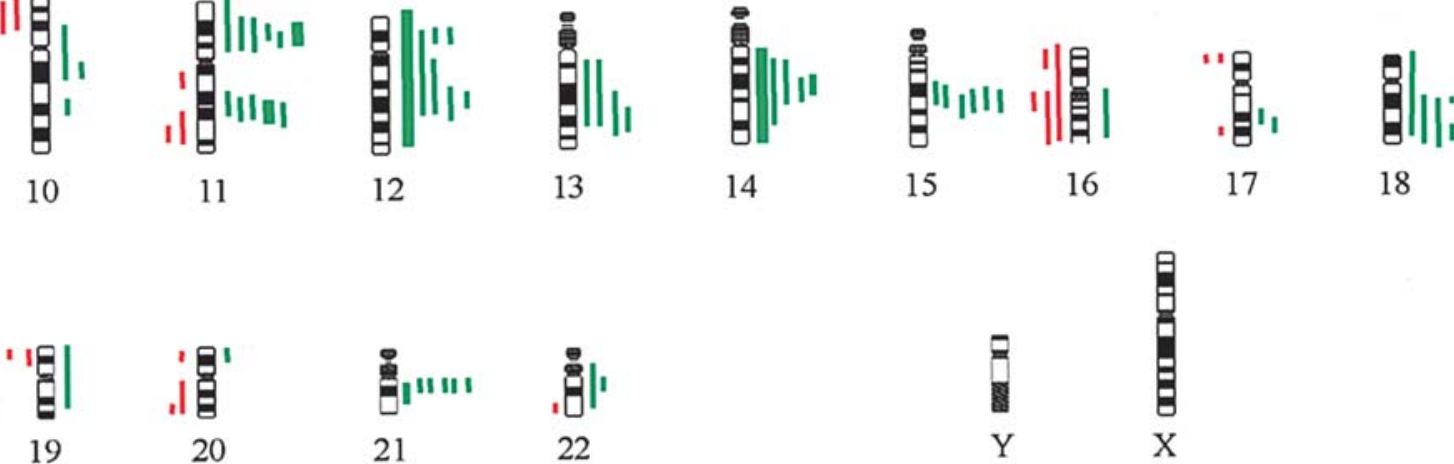

14

Figure 1. Summary of gains and losses of DNA sequence copy number in MPNST samples analyzed by CGH. Los
the right. Each line represents a genetic aberration seen in one sample. High-level gains are shown as thick lines.
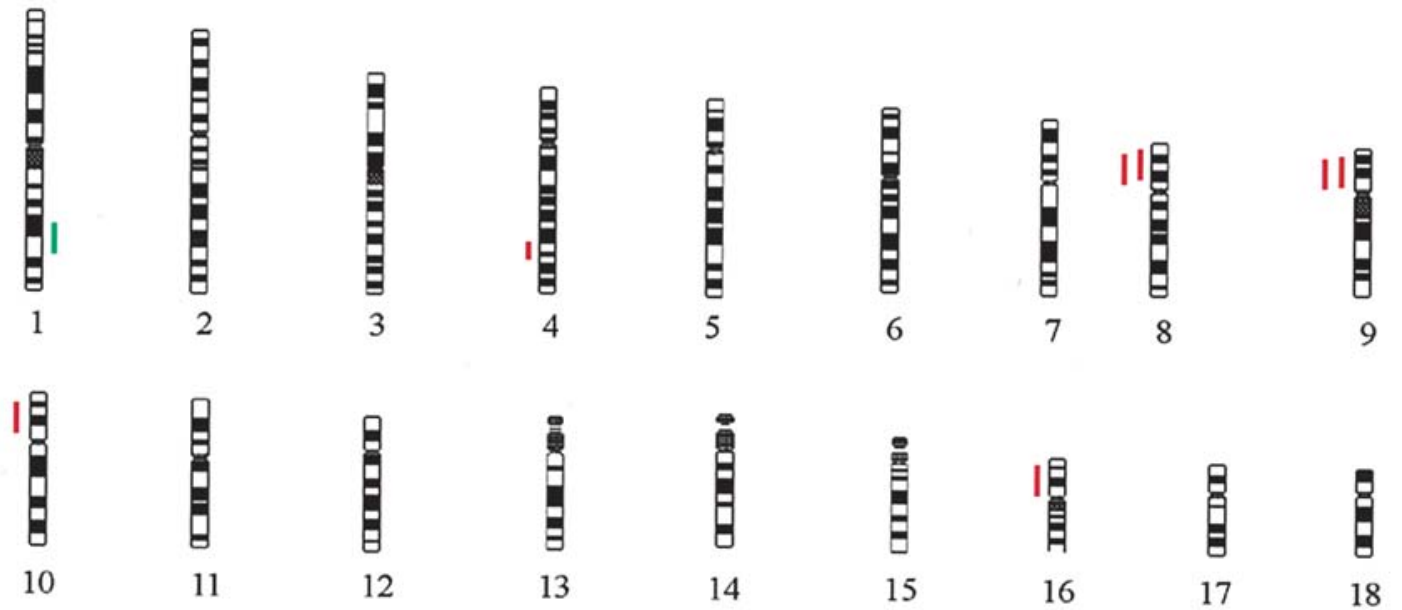

$$
\text { 珀 }
$$

19

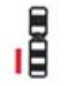

20

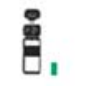

21

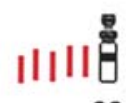

Figure 2. Summary of gains and losses of DNA sequence copy number in schwannoma. Losses are shown on the left side and gains on the right. Each line represents a genetic aberration seen in one sample.

cause (suicide), and 1 patient is still alive (Table I). Three patients had a local recurrence (cases 2,3, and 8), 1 patient had a pulmonary metastasis (case 5), 2 patients had both a local recurrence and a pulmonary metastasis (cases 1 and 7), and 2 patients had multiple tumor occurrences during the follow-up (cases 4 and 6). The average disease-free and survival periods were 15 months (range 3-31 months) and 27 months (range 4-51 months), respectively.
All patients with schwannoma are alive and free from local recurrence or metastasis. The average disease-free period was 46 months (range 20-96 months).

Metaphase $C G H$. Fresh-frozen tissue specimens from 8 MPNSTs and 8 schwannomas obtained from 16 patients were analyzed by metaphase CGH. Table II demonstrates the copy number changes in MPNSTs and schwannomas 
Table III. Results of microarray CGH in 5 malignant peripheral nerve sheath tumors.

\begin{tabular}{|c|c|c|c|c|c|c|c|}
\hline \multirow[b]{2}{*}{ Target index } & \multirow[b]{2}{*}{ Name of DNA clone } & \multirow[b]{2}{*}{ Location } & \multicolumn{5}{|c|}{ Case number } \\
\hline & & & 1 & 2 & 3 & 4 & 8 \\
\hline 24 & U32389 & $2 \mathrm{p}$ tel & 1.16 & 1.33 & 0.97 & 1.48 & 1.41 \\
\hline 25 & 2PTEL27 & $2 \mathrm{p}$ tel & 1.25 & 1.31 & 0.91 & 1.19 & 1.46 \\
\hline 27 & MSH2,KCNK12 & $2 \mathrm{p} 22.3-2 \mathrm{p} 22.1$ & 1.31 & 1.59 & 1.05 & 1.2 & 1.28 \\
\hline 60 & DDX15 & $4 p 15.3$ & 1.19 & 1.29 & 1.08 & 1.28 & 1.4 \\
\hline 71 & DAB2 & $5 \mathrm{p} 13$ & 1.26 & 1.44 & 1.21 & 1.34 & 1.19 \\
\hline 74 & EGRl & $5 q 31.1$ & 0.82 & 0.81 & 0.89 & 0.82 & 0.85 \\
\hline 91 & EGFR & 7p12.3-p12.1 & 1.86 & 1.94 & 1.26 & 1.22 & 1.55 \\
\hline 95 & CDK6 & 7q21-q22 & 1.79 & 1.2 & 1.17 & 0.99 & 1.29 \\
\hline 103 & $C T S B$ & 8 p22 & 0.76 & 0.84 & 0.79 & 0.85 & 0.94 \\
\hline 129 & GATA3 & $10 \mathrm{p} 15$ & 0.76 & 0.56 & 0.79 & 0.79 & 0.92 \\
\hline 195 & $C D H 1$ & $16 q 22.1$ & 0.79 & 0.65 & 0.76 & 0.7 & 0.86 \\
\hline 200 & stSG30213 & $16 q$ tel & 0.66 & 1.29 & 0.82 & 0.79 & 0.82 \\
\hline 203 & WI-14673 & $17 \mathrm{p}$ tel & 0.78 & 0.84 & 0.85 & 0.81 & 0.83 \\
\hline 229 & LAMA3 & $18 \mathrm{q} 11.2$ & 1.56 & 1.02 & 1.24 & 1.2 & 1.31 \\
\hline 242 & GLTSCR2,SULT2A1 & $19 q 13.32$ & 084 & 0.77 & 0.99 & 0.85 & 0.84 \\
\hline
\end{tabular}

Bold, gain; italic, loss.

detected by metaphase CGH. In all 8 MPNSTs, the total aberration number was 138 with a mean value of 17.3 (range, 9-24) aberrations per sample. The number of gains and losses were 110 (mean, 13.8) and 28 (mean, 3.5), respectively. The altered chromosomal regions in MPNSTs are summarized in Fig. 1. The most frequent gains were located in $4 \mathrm{q} 26,6 \mathrm{q}(7$ tumors each), 4q12-q26, 11q14, 15q21, 21q21 (6 tumors each), 5p14, 5q21, 11q14-q22, 12q21, and 14q21 (5 tumors each). The most frequent losses were seen in 16q21 (3 tumors), 1p36, 1q41-qter, 10p12-pter, 11q23, 16p13-pter, 17p13, and 19 p13 (2 tumors each). There were no differences regarding the frequency and distribution of chromosomal aberrations between the 3 sporadic and 5 NF1-associated MPNSTs. The youngest patient (case 7) with a rush tumor progression had the highest number of aberrations among the 8 patients.

In contrast, metaphase CGH detected genomic abnormalities in 5 of 8 schwannomas $(63 \%)$. The total aberration number was 17 (average, 2.1 per sample). The number of losses (15) was larger than that of gains (2). The most common alteration was loss of a whole arm of $22 \mathrm{q}$, which was found in 5 of $8(63 \%)$ schwannomas. Loss of $8 p$ and loss of $9 p$ was observed in 2 cases, each. The altered chromosomal regions in schwannomas are summarized in Fig. 2.

Microarray $C G H$. In order to investigate these chromosomal aberrations with a higher resolution and sensitivity, microarray CGH was employed to identify the genes with copy number aberration in a series of 5 MPNSTs. These 5 cases were selected among 8 MPNSTs with abundant aberrations. Aberrations were detected in all 5 MPNSTs. Table III demonstrates the results of microarray $\mathrm{CGH}$ and a summary of the results.
Genes detected as a gain in $\geq 4$ cases included EGFR, DAB2, MSH2, 2PTEL27, DDX15, CDK6, and LAMA3; genes identified as a loss in $\geq 4$ cases included CDH1, GLTSCR2, EGR1, CTSB, GATA3, stSG30213, and WI-14673.

To calculate a concordance rate of metaphase CGH and microarray $\mathrm{CGH}$, we compared the locus which was altered in microarray $\mathrm{CGH}$ with the result of metaphase $\mathrm{CGH}$. The average concordance rate was $66 \%$ (individual cases: 58,76 , $55,86,57 \%)$.

\section{Discussion}

Five of 8 schwannomas had a loss in the long arm of chromosome 22. The loss of $22 \mathrm{q}$, which harbors NF2, has been the only common genetic alteration reported in schwannomas to date (10-15). The NF2 gene may play an important role in the pathogenesis of schwannomas without involvement of other chromosomal regions (10). The loss of 22q12 was seen in schwannomas by metaphase $\mathrm{CGH}$, but not frequently in MPNSTs (one case). The mechanisms of formation of schwannoma and MPNST seem to be quite different.

The aberration detected in MPNST by metaphase CGH has been reported in three series (16-19). In the current study, the number of chromosomal gains in MPNSTs detected by metaphase $\mathrm{CGH}$ was larger than that of losses. Our results were consistent with the data obtained by chromosomal banding analysis of MPNSTs (20-22). This tendency was also observed by previous studies $(16,23)$. High incidence of gains suggests that the activation of proto-oncogenes may be predominant in MPNST during tumor progression as compared to inactivation of tumor suppressor genes. On the other hand, 
Lothe et al (24) reported that the number of losses was larger than that of gains. This could be partially explained by the difference in the definition of the aberrations between the two studies.

Gains were frequently observed in the whole arm of chromosome 4 and a long arm of chromosome 6 (7 cases each). In these chromosomes, genes such as DDX15, PDGFRA, KIT, ESR and MYB are located. The gains in chromosomes 7 and 8 were less frequent; however, these gains mostly consisted of high-level gains. Although gain in the chromosome 17 which included p53 (17p13.1) was reported to be frequent $(16,25)$, in the current study, it was observed in only 2 cases. Moreover, microarray CGH revealed a loss of p53 (17p13.1) in 3 cases. The gain of 8q was observed in 4 cases, including 3 high-level gains in the current study. According to Schmidt et al (25), and Mechtersheimer et al (16), the frequent gains included chromosomes 5p, 7, 8q, $15 q, 12 q$, and $17 q$ and losses included $9 p, 13 q$, and $1 p$. In contrast, Koga et al reported a different tendency to that of previous reports; the number of losses was larger than that of gains. The losses in chromosomes 17, 19, and 22q were frequently seen in the report (18); however, in our analysis, they were seen in only one or two cases.

As for correlation between the clinical course and experimental results, the number of cases is too small to make a statistical analysis. However, the patient who was youngest and had rush clinical course had a large number of aberrations. The patient developed multiple pulmonary metastases and a local relapse in a short period after the tumor excision. Further analysis is demanded to clarify these relations in the future.

Aberrations of several genes were detected in 5 MPNSTs by microarray CGH. The genes detected as gains in all 5 cases were EGFR (epidermal growth factor receptor, 7p12) and DAB2 (disabled homolog 2, 5p13). EGFR expression being associated with the development of schwann cell-derived tumors has already been reported in a few papers $(26,27)$. Although schwann cells usually lack EGFR, NF1-related tumors express EGFR, and the tumor progression was stimulated by EGF in vitro. Inhibition of the EGFR molecule (e.g. antagonists to the EGF receptor ) could become a useful treatment for MPNSTs. Mitogen-responsive phosphoprotein, DAB2 (disabled homolog 2) located in 5p13, is expressed in normal ovarian epithelial cells but is down-regulated or absent from ovarian carcinoma cell lines (28). However, it has not been reported in neurogenic tumors. Gains of the following genes were detected in 4 of 5 MPNSTs: MSH2 (mismatch homolog 2), DDX15 [DEAD/H (Asp-Glu-Ala-Asp/His) box polypeptide 15], CDK6 (cyclin-dependent kinase 6), and LAMA3 (laminin, alpha 3).

The genes detected as loss were as follows: CDH1 (cadherin type 1, 16q22.1); tumor supressor gene, EGR1 (early growth response 1, 5q31.1); CTSB (cathepsin B, 8p22); GATA3 (GATA binding protein 3, 10p15); and GLTSCR2 (glioma suppressor candidate region gene 2, 19q13.32). CDH1 mutates in gastric, breast, colorectal, thyroid, and ovarian cancers (29-31). Cadherin is the $\mathrm{Ca}^{2+}$-dependent cell adhesion which has been known to be expressed in normal and reactive schwann cells. Loss of function of cadherin 1 is thought to contribute to progression in cancer by increasing proliferation, invasion, and/or metastasis. Aberrations of EGR1, CTSB, Cathepsin D, GLTSCR2, and GATA3 have not been identified in MPNST-related papers, excluding GLTSCR2 aberration in glioma development (32).

Gain of $8 \mathrm{q}$ may be associated with gain of MYC (8q24.12-q24.13). The gain of $8 \mathrm{q}$ was seen in 4 of 8 cases by metaphase $\mathrm{CGH}$ in this study; however, microarray CGH did not reveal a gain of MYC in any of the 5 cases. MYB [v-myb myeloblastosis viral oncogene homolog (avian), 6q22-q23] aberration was also suspected in 7 cases by metaphase CGH in the current study, but it wasn't detected by microarray $\mathrm{CGH}$. Prevalence of microarray CGH may lead to the more precise analysis of genomic analysis.

When comparing the results of metaphase and microarray $\mathrm{CGH}$, the average concordance rate between the 2 techniques was $66 \%$ (range, $55-86 \%$ ). This was mainly because losses could not be detected by metaphase $\mathrm{CGH}$ as much as by microarray $\mathrm{CGH}$. If the gain and loss coexist in a narrow lesion, they can't be detected due to low resolutional activity of metaphase CGH. Hybridization to an array of mapped sequences instead of metaphase chromosomes could overcome the limitations of metaphase CGH. Metaphase CGH could be a reliable screening method before applying microarray $\mathrm{CGH}$. Microarray CGH targets the genes with which we can prepare and construct the cDNA array. On the other hand, metaphase CGH could cover a whole DNA to detect the aberration where the regions contain unknown genes.

\section{Acknowledgements}

Supported in part by a Grant-in-Aid for Clinical Cancer Research and a Grant-in-Aid for Cancer Research from the Ministry of Health, Labor, and Welfare (14S-4 and -5), by a Grant-in-Aid for General Scientific Research from the Ministry of Education, Science, Sports, and Culture (no. 14370464), and by a Grant-in-Aid from Japan Orthopaedics and Traumatology Foundation Inc. (J.O.T.F. Grant no. 0134).

\section{References}

1. Enzinger FM and Weiss SW: Malignant tumors of the peripheral nerves. 3rd edition, St Louis, Mosby, 1995.

2. Mautner VF, Lindenau M, Koppen J, Hazim W and Kluwe L: (Type 2 neurofibromatosis without acoustic neuroma). Zentralbl Neurochir 56: 83-87, 1995.

3. Decker HJ, Cannizzaro LA, Mendez MJ, Leong SP, Bixenman H, Berger C and Sandberg AA: Chromosomes 17 and 22 involved in marker formation in neurofibrosarcoma in von Recklinghausen disease. A cytogenetic and in situ hybridization study. Hum Genet 85: 337-342, 1990.

4. Perry A, Kunz SN, Fuller CE, Banerjee R, Marley EF, Liapis H, Watson MA and Gutmann DH: Differential NF1, p16, and EGFR patterns by interphase cytogenetics (FISH) in malignant peripheral nerve sheath tumor (MPNST) and morphologically similar spindle cell neoplasms. J Neuropathol Exp Neurol 61: 702-709, 2002.

5. Pinkel D, Segraves R, Sudar D, Clark S, Poole I, Kowbel D, Collins C, Kuo WL, Chen C, Zhai Y, Dairkee SH, Ljung BM, Gray JW and Albertson DG: High resolution analysis of DNA copy number variation using comparative genomic hybridization to microarrays. Nat Genet 20: 207-211, 1998.

6. Kallioniemi A, Kallioniemi OP, Sudar D, Rutovitz D, Gray JW, Waldman F and Pinkel D: Comparative genomic hybridization for molecular cytogenetic analysis of solid tumors. Science 258 : 818-821, 1992.

7. Enneking WF, Spanier SS and Goodman MA: A system for the surgical staging of musculoskeletal sarcoma. Clin Orthop 153: 106-120, 1980. 
8. Elias A, Ryan L, Sulkes A, Collins J, Aisner J and Antman KH: Response to mesna, doxorubicin, ifosfamide, and dacarbazine in 108 patients with metastatic or unresectable sarcoma and no prior chemotherapy. J Clin Oncol 7: 1208-1216, 1989.

9. Bruder CE, Hirvela C, Tapia-Paez I, Fransson I, Segraves R, Hamilton G, Zhang XX, Evans DG, Wallace AJ, Baser ME, Zucman-Rossi J, Hergersberg M, Boltshauser E, Papi L, Rouleau GA, Poptodorov G, Jordanova A, Rask-Andersen H, Kluwe L, Mautner V, Sainio M, Hung G, Mathiesen T, Moller C, Pulst SM, Harder H, Heiberg A, Honda M, Niimura M, Sahlen S, Blennow E, Albertson DG, Pinkel D and Dumanski JP: High resolution deletion analysis of constitutional DNA from neurofibromatosis type 2 (NF2) patients using microarray-CGH. Hum Mol Genet 10: 271-282, 2001.

10. Antinheimo J, Sallinen SL, Sallinen P, Haapasalo H, Helin H, Horelli-Kuitunen N, Wessman M, Sainio M, Jaaskelainen J and Carpen O: Genetic aberrations in sporadic and neurofibromatosis 2 (NF2)-associated schwannomas studied by comparative genomic hybridization (CGH). Acta Neurochir 142: 1095-1104, 2000.

11. Bello MJ, de Campos JM, Kusak ME, Vaquero J, Sarasa JL, Pestana A and Rey JA: Clonal chromosome aberrations in neurinomas. Genes Chromosomes Cancer 6: 206-211, 1993.

12. Couturier J, Delattre O, Kujas M, Philippon J, Peter M, Rouleau G, Aurias A and Thomas G: Assessment of chromosome 22 anomalies in neurinomas by combined karyotype and RFLP analyses. Cancer Genet Cytogenet 45: 55-62, 1990.

13. Mark J: The chromosomal findings in seven human neurinomas and one neurosarcoma. Acta Pathol Microbiol Scand (A) 80: 61-70, 1972.

14. Stenman G, Kindblom LG, Johansson M and Angervall L: Clonal chromosome abnormalities and in vitro growth characteristics of classical and cellular schwannomas. Cancer Genet Cytogenet 57: 121-131, 1991.

15. Trofatter JA, MacCollin MM, Rutter JL, Murrell JR, Duyao MP, Parry DM, Eldridge R, Kley N, Menon AG, Pulaski K, et al: A novel moesin-, ezrin-, radixin-like gene is a candidate for the neurofibromatosis 2 tumor suppressor. Cell 72: 791-800, 1993.

16. Mechtersheimer G, Otano-Joos M, Ohl S, Benner A, Lehnert T, Willeke F, Moller P, Otto HF, Lichter P and Joos S: Analysis of chromosomal imbalances in sporadic and NF1-associated peripheral nerve sheath tumors by comparative genomic hybridization. Genes Chromosomes Cancer 25: 362-369, 1999.

17. Schmidt H, Wurl P, Taubert H, Meye A, Bache M, Holzhausen HJ and Hinze R: Genomic imbalances of $7 p$ and $17 \mathrm{q}$ in malignant peripheral nerve sheath tumors are clinically relevant. Genes Chromosomes Cancer 25: 205-211, 1999.

18. Koga T, Iwasaki H, Ishiguro M, Matsuzaki A and Kikuchi M: Losses in chromosomes 17, 19, and 22q in neurofibromatosis type 1 and sporadic neurofibromas: a comparative genomic hybridization analysis. Cancer Genet Cytogenet 136: 113-120, 2002.

19. Koga T, Iwasaki H, Ishiguro M, Matsuzaki A and Kikuchi M: Frequent genomic imbalances in chromosomes 17, 19, and 22q in peripheral nerve sheath tumours detected by comparative genomic hybridization analysis. J Pathol 197: 98-107, 2002.
20. Glover TW, Stein CK, Legius E, Andersen LB, Brereton A and Johnson S: Molecular and cytogenetic analysis of tumors in von Recklinghausen neurofibromatosis. Genes Chromosomes Cancer 3: 62-70, 1991.

21. Jhanwar SC, Chen Q, Li FP, Brennan MF and Woodruff JM: Cytogenetic analysis of soft tissue sarcomas. Recurrent chromosome abnormalities in malignant peripheral nerve sheath tumors (MPNST). Cancer Genet Cytogenet 78: 138-144, 1994.

22. Mertens F, Rydholm A, Bauer HF, Limon J, Nedoszytko B, Szadowska A, Willen H, Heim S, Mitelman F and Mandahl N: Cytogenetic findings in malignant peripheral nerve sheath tumors. Int J Cancer 61: 793-798, 1995.

23. Schmidt H, Taubert H, Wurl P, Bache M, Bartel F, Holzhausen HJ and Hinze R: Cytogenetic characterization of six malignant peripheral nerve sheath tumors: comparison of karyotyping and comparative genomic hybridization. Cancer Genet Cytogenet 128: 14-23, 2001

24. Lothe RA, Karhu R, Mandahl N, Mertens F, Saeter G, Heim S, Borresen-Dale AL and Kallioniemi OP: Gain of 17q24-qter detected by comparative genomic hybridization in malignant tumors from patients with von Recklinghausen's neurofibromatosis. Cancer Res 56: 4778-4781, 1996.

25. Schmidt H, Taubert H, Meye A, Wurl P, Bache M, Bartel F, Holzhausen HJ and Hinze R: Gains in chromosomes 7, 8q, 15q and $17 \mathrm{q}$ are characteristic changes in malignant but not in benign peripheral nerve sheath tumors from patients with Recklinghausen's disease. Cancer Lett 155: 181-190, 2000.

26. DeClue JE, Heffelfinger S, Benvenuto G, Ling B, Li S, Rui W, Vass WC, Viskochil D and Ratner N: Epidermal growth factor receptor expression in neurofibromatosis type 1-related tumors and NF1 animal models. J Clin Invest 105: 1233-1241, 2000.

27. Li H, Velasco-Miguel S, Vass WC, Parada LF and DeClue JE: Epidermal growth factor receptor signaling pathways are associated with tumorigenesis in the Nf1:p53 mouse tumor model. Cancer Res 62: 4507-4513, 2002.

28. Fazili Z, Sun W, Mittelstaedt S, Cohen C and Xu XX: Disabled2 inactivation is an early step in ovarian tumorigenicity. Oncogene 18: 3104-3113, 1999.

29. Keller G, Vogelsang H, Becker I, Hutter J, Ott K, Candidus S, Grundei T, Becker KF, Mueller J, Siewert JR and Hofler H: Diffuse type gastric and lobular breast carcinoma in a familial gastric cancer patient with an E-cadherin germline mutation. Am J Pathol 155: 337-342, 1999.

30. Ikonen T, Matikainen M, Mononen N, Hyytinen ER, Helin HJ, Tommola S, Tammela TL, Pukkala E, Schleutker J, Kallioniemi OP and Koivisto PA: Association of E-cadherin germ-line alterations with prostate cancer. Clin Cancer Res 7: 3465-3471, 2001

31. Katoh M: Identification and characterization of human SNAIL3 (SNAI3) gene in silico. Int J Mol Med 11: 383-388, 2003.

32. Smith JS, Tachibana I, Pohl U, Lee HK, Thanarajasingam U, Portier BP, Ueki K, Ramaswamy S, Billings SJ, Mohrenweiser HW, Louis DN and Jenkins RB: A transcript map of the chromosome $19 \mathrm{q}$-arm glioma tumor suppressor region. Genomics 64: 44-50, 2000 